\title{
Void Structures in Regularly Patterned ZnO Nanorods Grown with the Hydrothermal Method
}

\author{
Yu-Feng Yao, Chen-Hung Shen, Wei-Fang Chen, Pei-Ying Shih, \\ Wang-Hsien Chou, Chia-Ying Su, Horng-Shyang Chen, Che-Hao Liao, Wen-Ming Chang, \\ Yean-Woei Kiang, and C. C. Yang
}

Institute of Photonics and Optoelectronics and Department of Electrical Engineering, National Taiwan University, 1 Roosevelt Road, Section 4, Taipei 10617, Taiwan

Correspondence should be addressed to C. C. Yang; ccy@cc.ee.ntu.edu.tw

Received 14 December 2013; Accepted 14 February 2014; Published 19 March 2014

Academic Editor: Wen Lei

Copyright (C) 2014 Yu-Feng Yao et al. This is an open access article distributed under the Creative Commons Attribution License, which permits unrestricted use, distribution, and reproduction in any medium, provided the original work is properly cited.

\begin{abstract}
The void structures and related optical properties after thermal annealing with ambient oxygen in regularly patterned $\mathrm{ZnO}$ nanrorod (NR) arrays grown with the hydrothermal method are studied. In increasing the thermal annealing temperature, void distribution starts from the bottom and extends to the top of an NR in the vertical ( $c$-axis) growth region. When the annealing temperature is higher than $400^{\circ} \mathrm{C}$, void distribution spreads into the lateral ( $m$-axis) growth region. Photoluminescence measurement shows that the $\mathrm{ZnO}$ band-edge emission, in contrast to defect emission in the yellow-red range, is the strongest under the $n$ - $\mathrm{ZnO} \mathrm{NR}$ process conditions of $0.003 \mathrm{M}$ in Ga-doping concentration and $300^{\circ} \mathrm{C}$ in thermal annealing temperature with ambient oxygen. Energy dispersive X-ray spectroscopy data indicate that the concentration of hydroxyl groups in the vertical growth region is significantly higher than that in the lateral growth region. During thermal annealing, hydroxyl groups are desorbed from the NR leaving anion vacancies for reacting with cation vacancies to form voids.
\end{abstract}

\section{Introduction}

Because of its large band gap of $3.36 \mathrm{eV}$ and high exciton binding energy of $\sim 60 \mathrm{meV}, \mathrm{ZnO}$ nanostructures have attracted much research attention for nanodevice applications, including light-emitting devices [1], solar cells [2], power generators [3], and others [4]. ZnO nanostructures, such as nanorods (NRs) [5], nanowires [6], nanotubes [7], and nanowalls [7], have been widely investigated in the past several years due to their superior electrical and optical properties, when compared with a planar structure. In the device applications of $\mathrm{ZnO}$ NRs, it is important not only to grow $\mathrm{ZnO}$ NRs with a high degree of regularity and uniformity in terms of their height and cross-sectional size, but also to accurately control their positions. Good controls of NR position and shape can improve the performances of the fabricated electronics and optoelectronics devices $[8,9]$. A few vapor-phase methods have been used for the growth of $\mathrm{ZnO}$ NRs, including metalorganic chemical vapor deposition (MOCVD) [10], pulsed laser deposition [11], and radiofrequency magnetron sputtering [12]. A ZnO NR formed via the hydrothermal method has attracted attention because of its advantages of fast, large-scale, low-cost, and low-temperature $\left(<100^{\circ} \mathrm{C}\right)$ growth. Selective-area growth (SAG) on a patterned mask has been proved to be an effective method for localizing the growth of $\mathrm{ZnO}$ nanostructures. Various lithography methods for SAG patterning have been reported, including nanoimprint [13], interference [14], electron-beam writing [15], and nanosphere coating [16]. For a high-throughput, low-cost, and large-area fabrication, nanoimprint lithography is a preferred choice.

Although the growth of $\mathrm{ZnO}$ NRs with the hydrothermal method has the aforementioned advantages, it may result in a high defect density due to the low growth temperature. In particular, it has been reported that voids could be formed in a $\mathrm{ZnO}$ structure grown with the hydrothermal method [17-19]. However, although the existence of voids in a $\mathrm{ZnO}$ film [17], on a $\mathrm{ZnO}$ NR surface [18], or inside a ZnO NR after thermal annealing has been mentioned or briefly discussed [19], so far no detailed study on the void distribution inside a $\mathrm{ZnO} \mathrm{NR}$ 
and its formation condition and mechanism was reported, particularly in a regularly patterned $\mathrm{ZnO} \mathrm{NR}$ array grown with the hydrothermal method. In this paper, we first demonstrate the growth of regularly patterned $\mathrm{ZnO} \mathrm{NR}$ arrays on $\mathrm{GaN}$ template with the hydrothermal method based on the nanoimprint lithography technique. The optimum conditions of growth solution concentration, growth temperature, and growth duration are identified. Then, with the measurements of scanning electron microscopy (SEM), backscattering electron microscopy (BSEM), and transmission electron microscopy (TEM), including the observations of high-angle annular dark-field (HAADF) image and energy dispersive X-ray (EDX) spectrum, the void distributions and their formation mechanisms under various thermal annealing and Ga-doping conditions are investigated. Also, the emission properties under various conditions are explored with roomtemperature photoluminescence (PL) measurement.

In Section 2 of this paper, the fabrication procedures and growth conditions of regularly patterned $\mathrm{ZnO} \mathrm{NR}$ arrays are reported. The void microstructures under different thermal annealing and Ga-doping conditions are discussed in Section 3. Then, the optical characterization results are shown in Section 4. Discussions regarding the formation of voids are given in Section 5. Finally, conclusions are drawn in Section 6 .

\section{Growth of Regularly Patterned ZnO Nanorod Arrays}

The $\mathrm{ZnO} \mathrm{NR}$ arrays are grown on a $2 \mu \mathrm{m}$ undoped GaN template with a patterned $\mathrm{Si}_{3} \mathrm{~N}_{4}$ mask layer of $40 \mathrm{~nm}$ in thickness, which is deposited with plasma enhanced chemical vapor deposition. The GaN layer is grown with MOCVD at $1000^{\circ} \mathrm{C}$ on a $c$-plane sapphire substrate. The nanoimprint lithography technique is used for patterning the $\mathrm{Si}_{3} \mathrm{~N}_{4}$ mask with a triangular arrangement of circular holes of $350 \mathrm{~nm}$ in hole diameter and $1453 \mathrm{~nm}$ in pitch. Figure 1(a) shows the plan-view SEM image (with a JEOL JSM-7001F system at $15 \mathrm{kV}$ in electron acceleration voltage) of the patterned template used for $\mathrm{ZnO} \mathrm{NR}$ growth. In the hydrothermal growth process, after cleaning such a template is placed upside down in the growth solution for avoiding the accumulation of precipitates in the gaps between NRs. For undoped $\mathrm{ZnO} \mathrm{NR}$ growth, the aqueous solution for the hydrothermal reaction consists of equal-molar zinc nitrate hexahydrate and hexamethylenetetramine of controlled concentrations. Before use, the chemicals are well mixed in the solution and the precipitates are filtered. The template is immersed in the solution $10 \mathrm{~min}$ after the solution is heated to the designated growth temperature. Then, the sealed beaker containing the growth solution and the template is kept at the designated growth temperature for the designated growth duration.

Figures 1(b) $-1(\mathrm{~d})$ show the $30^{\circ}$ tilted SEM images of the growth results on the template with the growth durations of 10,30 , and $180 \mathrm{~min}$, respectively, when the concentration of the growth solution is $0.08 \mathrm{M}$ and the growth temperature is $80^{\circ} \mathrm{C}$. As shown in Figure $1(\mathrm{~b})$, multiple $\mathrm{ZnO}$ nucleation clusters are formed in each hole on the patterned mask after the growth duration of $10 \mathrm{~min}$. Each of those nucleation clusters can extend its length along the $c$-axis to form a small $\mathrm{NR}$, as shown in Figure 1(c). As the growth duration becomes longer, those small $\mathrm{ZnO}$ NRs in a hole can merge into a large hexagonal NR with the cross-sectional size larger than the hole diameter, as shown in Figure 1(d). The larger crosssectional size of the grown NRs implies that both the vertical growth (along the $c$-axis) and lateral growth (along the $m$ axis) of $\mathrm{ZnO}$ occur during the formation of an NR. Here, one can see that the top faces of the NRs are quite flat. The cross-sectional size (the distance between two parallel sides of the hexagonal shape) is about $850 \mathrm{~nm}$. The height of this $\mathrm{ZnO} \mathrm{NR}$ array is around $2 \mu \mathrm{m}$. Figure $1(\mathrm{e})$ shows a largerscale tilted SEM image of the same sample illustrating the uniformity of the $\mathrm{ZnO} \mathrm{NR}$ array. It is found that the $\mathrm{ZnO}$ NR growths with higher growth solution concentrations (say, $0.1 \mathrm{M}$ ), higher growth temperatures (say, $95^{\circ} \mathrm{C}$ ), or longer growth durations (say, $300 \mathrm{~min}$ ) lead to coalesced growth of NRs to form thin films. In the hydrothermal reaction study, we also consider the growth of $n-\mathrm{ZnO} \mathrm{NR}$ arrays by doping $\mathrm{ZnO}$ with $\mathrm{Ga}$ through the addition of gallium nitrate hydrate to the growth solution of various concentrations. Figure 1(f) shows the tilted SEM image of a Ga-doped ZnO NR array under the same growth conditions as those for Figures $1(\mathrm{~b})-1(\mathrm{e})$. The Ga doping is implemented by adding gallium nitrate hydrate of a designated concentration to the growth solution. The used concentration of gallium nitrate hydrate for growing the sample shown in Figure $1(\mathrm{f})$ is $0.003 \mathrm{M}$. The cross-sectional size of the Ga-doped $\mathrm{ZnO}$ NRs is smaller than that of the undoped NRs. The electron concentration of the grown $n$ - $\mathrm{ZnO}$ (a thin film growth of $300 \mathrm{~min}$ in growth duration) under the same growth conditions as those for the sample in Figure 1(f) is measured to give $2.57 \times 10^{19} \mathrm{~cm}^{-3}$. Since many undoped $\mathrm{ZnO}$ NR array samples in the following discussions are grown under the same growth condition as that for the sample shown in Figure 1(d) $(0.08 \mathrm{M}$ in growth solution concentration, $80^{\circ} \mathrm{C}$ in growth temperature, and $180 \mathrm{~min}$ in growth duration), this set of growth parameters will be referred to as the standard growth condition for undoped $\mathrm{ZnO} \mathrm{NR}$ array. By adding gallium nitrate hydrate of $0.003 \mathrm{M}$, the set of growth parameters will be referred to as the standard growth condition for Ga-doped $\mathrm{ZnO}$ NR array.

As shown in Figure 1(c), an NR is formed through the growth of multiple small rod structures first and then their mergence. Figures 2(a) and 2(b) show a cross-sectional TEM image of an NR and the close-up image around the bottom of the NR, respectively, based on the standard growth condition. The TEM specimens are prepared through the sample ablation by a focused ion beam. The TEM investigation is performed using a PhilipsTecnai F30 fieldemission electron microscope with an accelerating voltage of $300 \mathrm{kV}$ and a probe forming lens of $\mathrm{Cs}=1.2 \mathrm{~mm}$. In Figure 2(b), the dark line pattern dividing different domains indicates the merging process of the multiple nucleation clusters. During this process, the domain boundaries may evolve into threading dislocations as growth continues. In Figure 2(b), two dislocations are formed as indicated by the white arrows. As shown in Figure 2(a), one of them propagates to the top of the NR. The other extends toward 


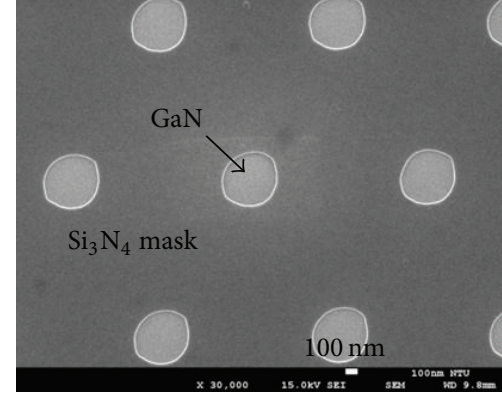

(a)

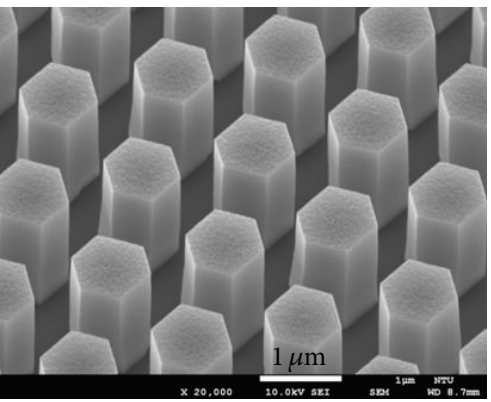

(d)

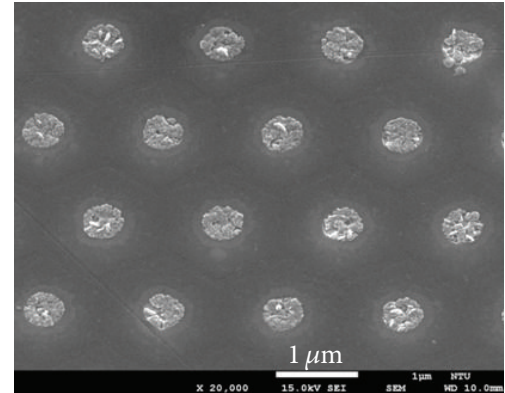

(b)

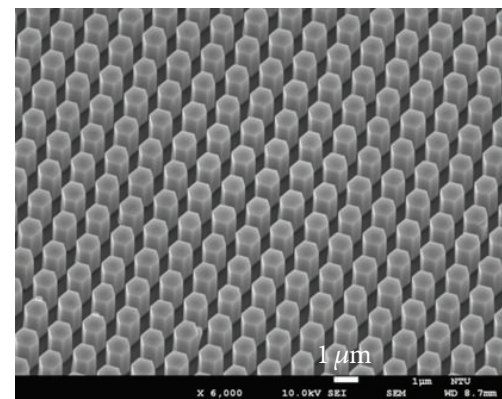

(e)

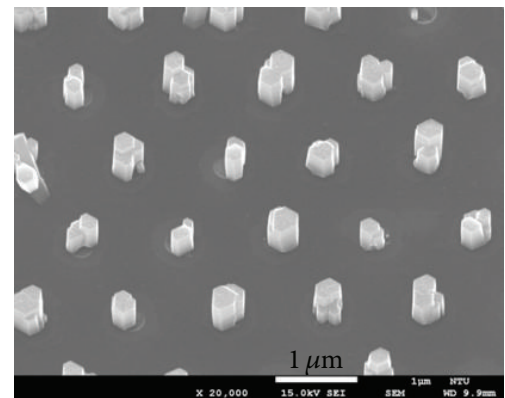

(c)

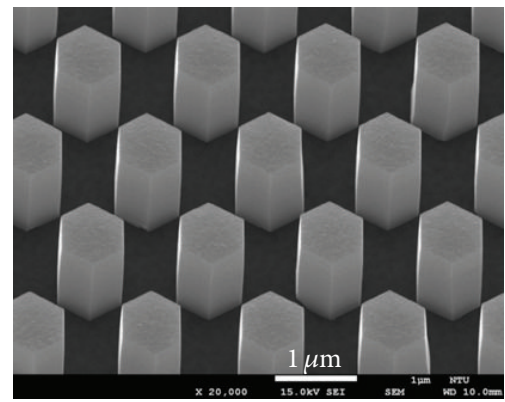

(f)

FIGURE 1: (a) Plan-view SEM image of a patterned template for ZnO NR growth. (b)-(d) $30^{\circ}$ tilted SEM images of the growth results on the template with the growth durations of 10,30 , and $180 \mathrm{~min}$, respectively, when the concentration of the growth solution is $0.08 \mathrm{M}$ and the growth temperature is $80^{\circ} \mathrm{C}$. (e) Larger-scale tilted SEM image of the same sample illustrating the uniformity of the ZnO NR array. (f) Tilted SEM image of a Ga-doped ZnO NR array sample under the same growth conditions as those in parts (b)-(e) and $0.003 \mathrm{M}$ in Ga-doping concentration.

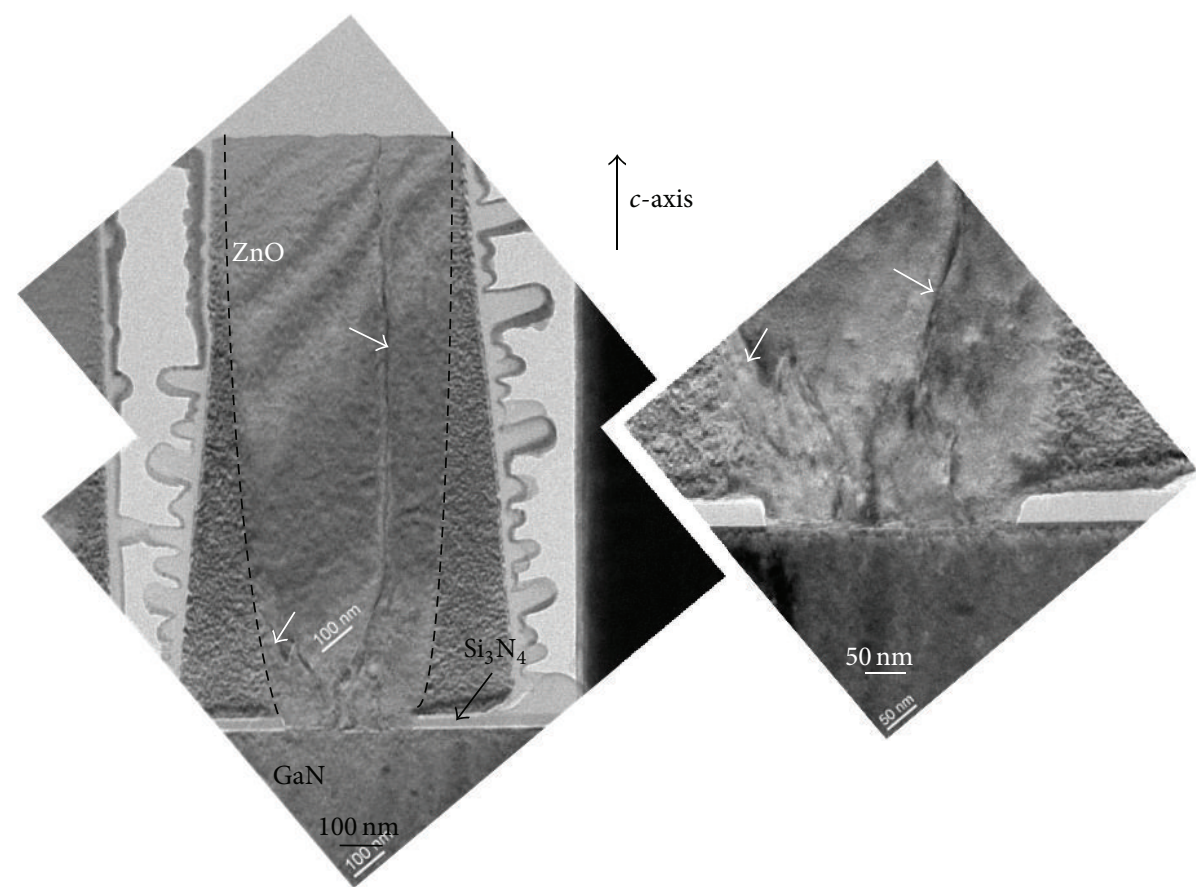

(a)

(b)

FIgURE 2: (a) and (b) Cross-sectional TEM image of an NR and the close-up image around the bottom of the NR, respectively. The arrows show the two dislocations. The two dashed curves divide the regions of the vertical and lateral growth regions. 
the upper-left direction. In this image, this dislocation stops at the boundary between two regions of different levels of surface roughness. As approximately divided by the two dashed curves in Figure 2(a), the relatively smoother and rougher regions correspond to the portions of vertical (along the $c$-axis) and lateral (along the $m$-axis) growths, as to be further discussed later. The left dislocation in Figure 2(a) can be bended in the lateral growth region such that it does not propagate toward the top of the NR.

\section{Void Formation in ZnO Nanorods}

Thermal annealing can improve the crystal and optical qualities of the grown $\mathrm{ZnO}$ NRs. Figures 3(b)-3(e) show the cross-sectional TEM images of undoped $\mathrm{ZnO}$ NRs after thermal annealing with ambient oxygen for $60 \mathrm{~min}$ at 200, 300,400 , and $500^{\circ} \mathrm{C}$, respectively. For comparison, the TEM image of an as-grown sample is also shown in Figure 3(a). The undoped $\mathrm{ZnO}$ NRs are grown under the standard growth condition. In the as-grown sample, no void structure can be seen in the $\mathrm{ZnO} \mathrm{NR}$. Voids are formed after thermal annealing. At $200^{\circ} \mathrm{C}$ in annealing temperature, the voids are small such that the image contrast is weak. A few voids are indicated by the arrows. Here, the voids are distributed around the lower central portion of the NR. As the annealing temperature increases, the void size and density become larger and its distribution extends upward to cover a larger area. With the annealing temperatures at 300 and $400^{\circ} \mathrm{C}$, the voids are distributed only in the region of vertical growth. In Figures 3(c) and 3(d), the dashed curves again indicate roughly the boundaries between the regions of vertical and lateral growths. When the annealing temperature is $500^{\circ} \mathrm{C}$, the void distribution reaches the top of the NR and extends into the region of lateral growth. As shown in Figures 3(d) and 3(e), the void size can be as large as $100 \mathrm{~nm}$.

The scenarios of void formation in Ga-doped $\mathrm{ZnO}$ NRs are quite different. Figures $4(\mathrm{a})-4(\mathrm{~d})$ show the cross-sectional TEM images of an as-grown Ga-doped $\mathrm{ZnO} \mathrm{NR}$, and Gadoped $\mathrm{ZnO}$ NRs thermally annealed at 200,300 , and $400^{\circ} \mathrm{C}$, respectively, with ambient oxygen for $60 \mathrm{~min}$. The Ga-doped $\mathrm{ZnO} \mathrm{NRs}$ are grown under the standard condition. Here, different from the case of undoped $\mathrm{ZnO} \mathrm{NR}$, essentially void is not formed under the annealing condition of $200^{\circ} \mathrm{C}$ in temperature. Voids are clearly seen when the annealing temperature becomes higher, as shown in Figures 4(c) and 4(d). Therefore, voids can be formed in a Ga-doped $\mathrm{ZnO}$ NR when it is annealed at a higher temperature, when compared with an undoped $\mathrm{ZnO}$ NR. To understand the crystal microstructures around voids, in Figures 5(b) and 5(c), we show two atomic-scale TEM images in the two regions across the void boundaries marked with the rectangles in Figure 5(a) in a Ga-doped $\mathrm{ZnO} \mathrm{NR}$ thermally annealed at $400^{\circ} \mathrm{C}$ with ambient oxygen for $60 \mathrm{~min}$ (the same as the sample shown in Figure 4(d)). Figures 5(d) and 5(e) show the Fouriertransform patterns of the whole TEM images in Figures 5(b) and 5(c), respectively. In Figures 5(b) and 5(c), the brighter regions correspond to the two neighboring voids around the marked areas in Figure 5(a). Here, one can see that the lattice fringes are continuous across the void boundaries. Also, as shown in Figures 5(d) and 5(e), the corresponding Fourier-transform patterns are quite coherent. These results indicate that during void formation in the thermal annealing process, the atomic arrangement follows the structure of the neighboring $\mathrm{ZnO}$ crystal.

The void structures in the NRs can also be seen with the observation of BSEM. Figure 6(a) shows the SEM image of four fallen undoped $\mathrm{ZnO}$ NRs grown under the standard condition before thermal annealing. The SEM image of the same sample after thermal annealing at $300^{\circ} \mathrm{C}$ for $60 \mathrm{~min}$ with ambient oxygen is shown in Figure 6(b). The SEM image of the same sample after the second annealing process at $400^{\circ} \mathrm{C}$ for $60 \mathrm{~min}$ with ambient oxygen is shown in Figure 6(c). Then, The SEM image of the same sample after the third annealing process at $500^{\circ} \mathrm{C}$ for $60 \mathrm{~min}$ with ambient oxygen is shown in Figure 6(d). Here, one can see that void cannot be observed with SEM either before or after thermal annealing. However, voids can be observed with BSEM, as shown in Figures 6(f)-6(h). Figures 6(e)-6(h) show the BSEM images corresponding to the SEM images in Figures 6(a)-6(d), respectively. The dark spots in Figures 6(f)-6(h) show the void distributions under different annealing conditions. The SEM images in Figures 7(a) and 7(b) show either the bottom or top faces of a few undoped $\mathrm{ZnO}$ NRs after the three-stage annealing process $\left(300,400\right.$, and then $\left.500^{\circ} \mathrm{C}\right)$. On a bottom face, one can see a circular protrusion, which corresponds to the $\mathrm{ZnO}$ portion in the patterned hole on the growth template. Figures $7(\mathrm{c})$ and $7(\mathrm{~d})$ show the corresponding BSEM images of Figures 7(a) and 7(b), respectively. Here, one can see that on a bottom face, voids distribute only in the protrusion portion, that is, the portion of vertical growth. On a top face, the voids distribute in a larger circular area. This result is consistent with those in Figures 3(e) and 4(d).

\section{Photoluminescence Measurement}

Figure 8 shows the PL spectra of undoped $\mathrm{ZnO} \mathrm{NR}$ array samples under the as-grown and the thermal annealing conditions of different ambient gases (air and oxygen). The NR array samples are grown under the standard condition. The thermal annealing conditions include $300^{\circ} \mathrm{C}$ in temperature and $60 \mathrm{~min}$ in duration. The PL measurement is excited by a HeCd laser at $325 \mathrm{~nm}$ with the incident power at $10 \mathrm{~mW}$. In each curve of Figure 8, a narrow peak around $375 \mathrm{~nm}$ due to the band-edge emission of $\mathrm{ZnO}$ and a broad hump in the range of $470-800 \mathrm{~nm}$ from defect emission can be observed. The small peak around $360 \mathrm{~nm}$ in the spectrum with ambient air originates from the band-edge emission of the GaN template. Because the spectral portions of band-edge and defect emissions can be well separated, the ratio of their individual integrated intensities can be used for indicating the optical quality of the NR array sample. Here, one can see that the defect emission is significantly weaker under the annealing condition of ambient oxygen. The integrated PL intensity ratios of band-edge emission over defect emission are $0.05,0.45$, and 2.11 in the as-grown case, the cases of annealing with ambient air, and annealing 


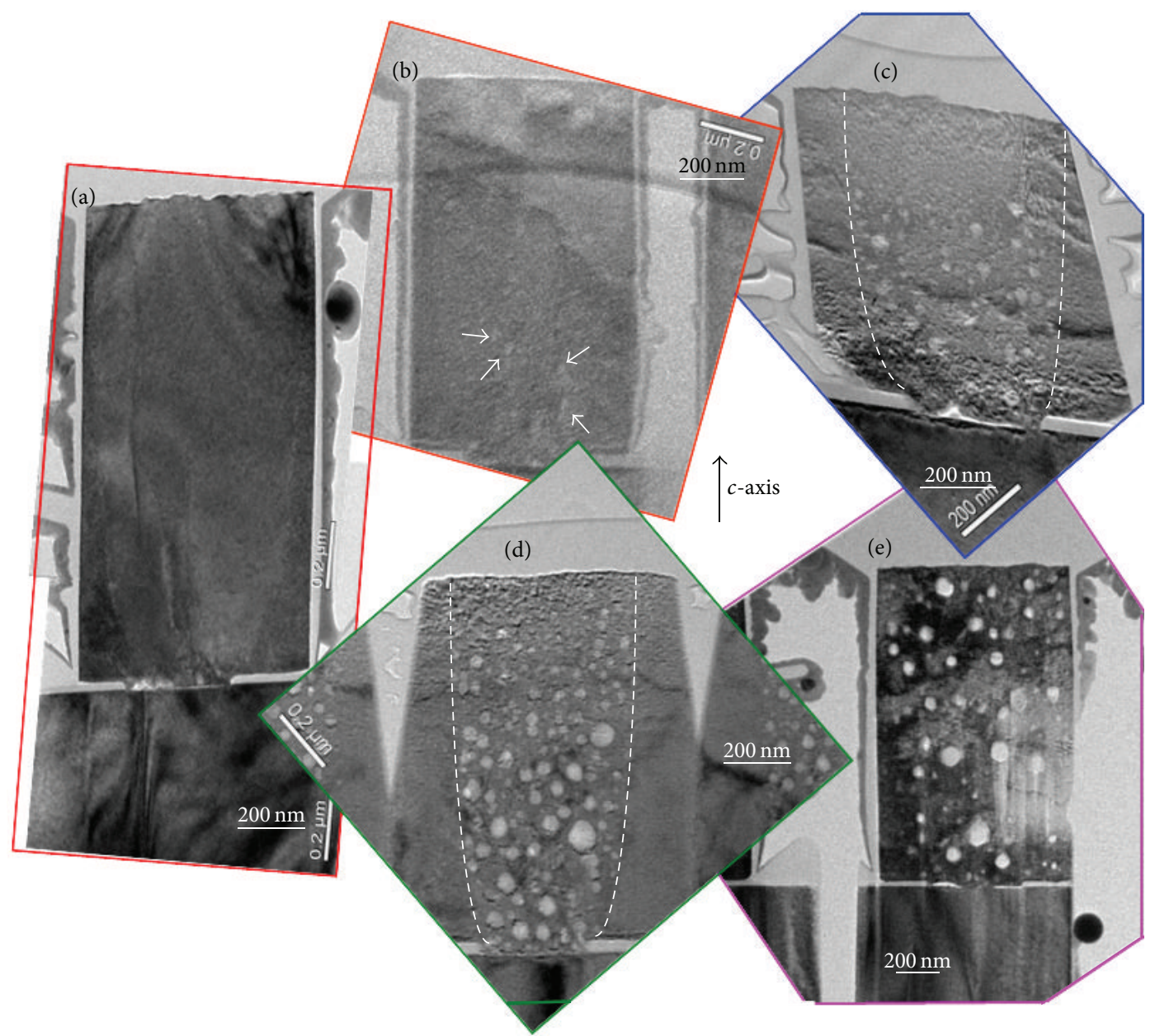

FIGURE 3: (a) Cross-sectional TEM image of an as-grown undoped ZnO NR sample. (b)-(e): Cross-sectional TEM images of undoped ZnO NRs after thermal annealing with ambient oxygen for $60 \mathrm{~min}$ at 200, 300, 400, and $500^{\circ} \mathrm{C}$, respectively. The ZnO NRs are grown under the standard condition.

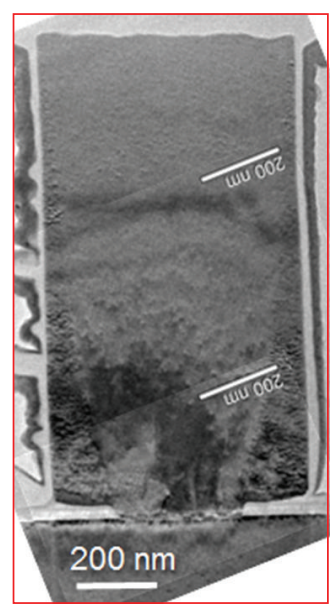

(a)

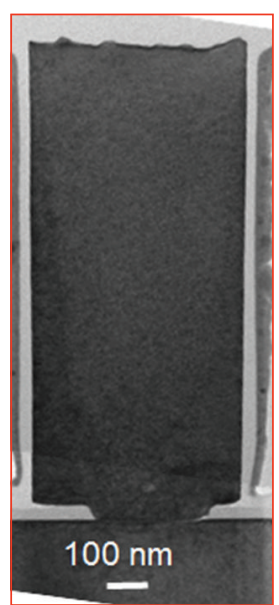

(b)

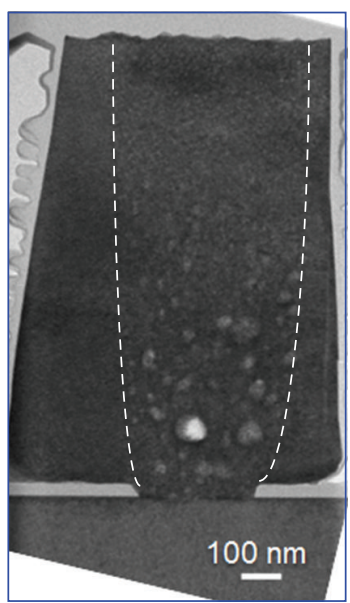

(c)

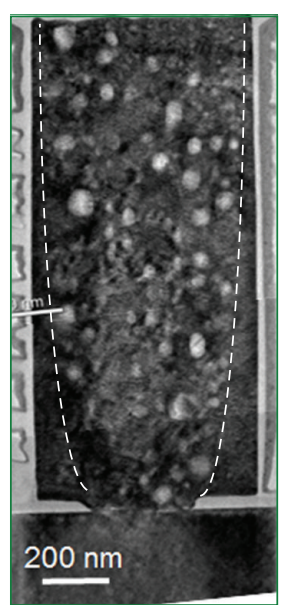

(d)

Figure 4: (a)-(d) Cross-sectional TEM images of an as-grown Ga-doped ZnO NR and Ga-doped ZnO NRs thermally annealed at 200, 300, and $400^{\circ} \mathrm{C}$, respectively, with ambient oxygen for $60 \mathrm{~min}$. The Ga-doped $\mathrm{ZnO}$ NRs are grown under the standard condition. 


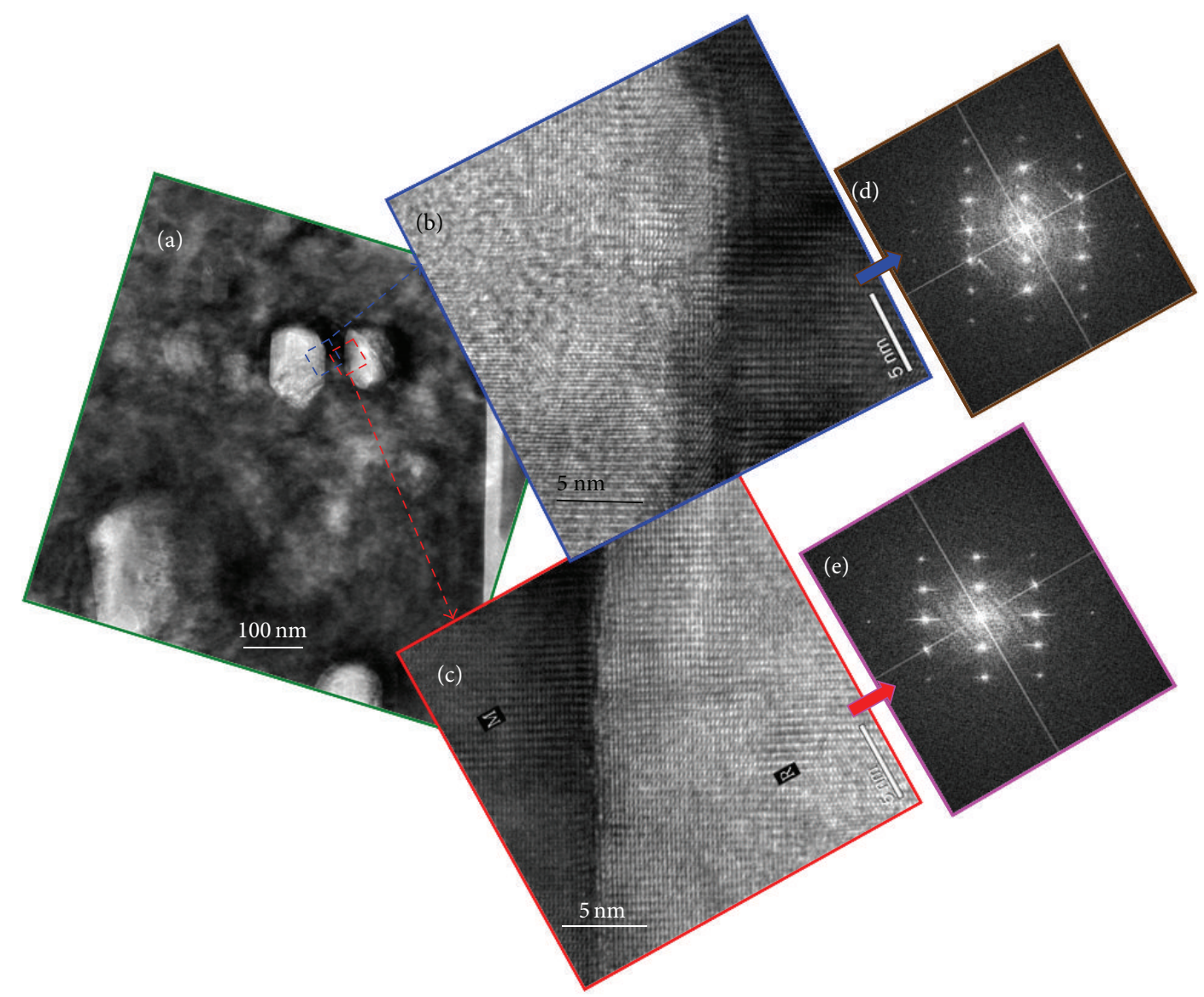

FIgURE 5: (a) Cross-sectional TEM image of a Ga-doped ZnO NR thermally annealed at $400^{\circ} \mathrm{C}$ with ambient oxygen for 60 min (the same as the sample shown in Figure 4(d)). (b) and (c) Atomic-scale TEM images in the regions marked with the two rectangles in part (a). (d) and (e) Fourier-transform patterns of the images in parts (b) and (c), respectively.

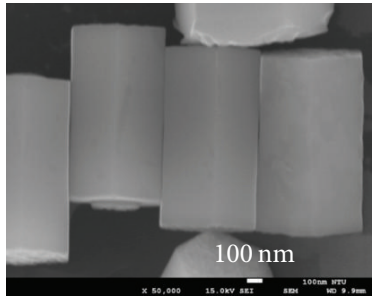

(a)

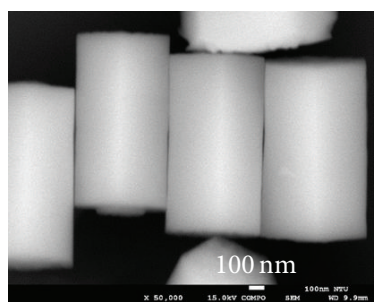

(e)

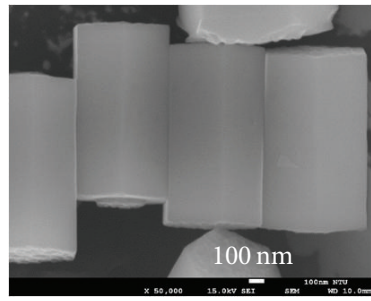

(b)

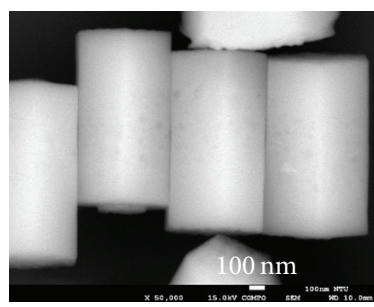

(f)

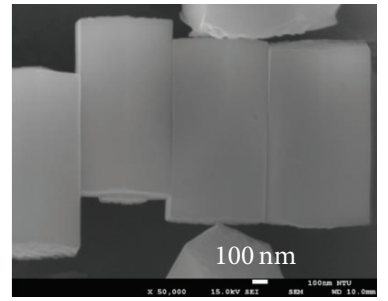

(c)

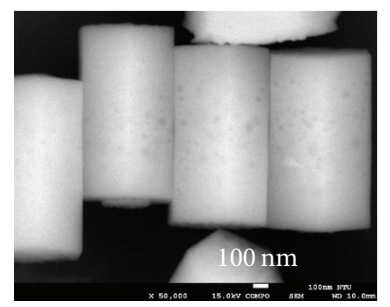

(g)

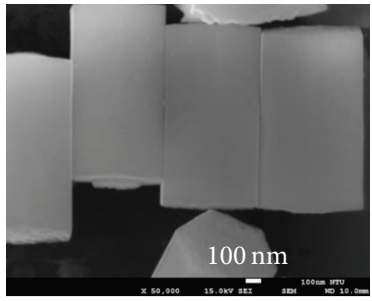

(d)

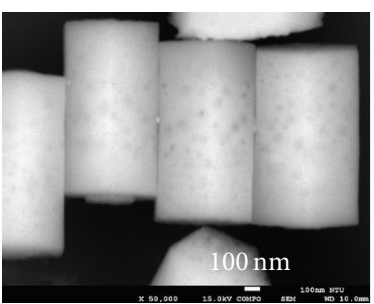

(h)

FIGURE 6: (a) SEM image of four fallen undoped ZnO NRs before thermal annealing. (b) SEM image of the sample in (a) after thermal annealing at $300^{\circ} \mathrm{C}$ for $60 \mathrm{~min}$ with ambient oxygen. (c) SEM image of the sample in (b) after the second annealing process at $400^{\circ} \mathrm{C}$ for 60 min with ambient oxygen. (d) SEM image of the sample in (c) after the third annealing process at $500^{\circ} \mathrm{C}$ for 60 min with ambient oxygen. (e)-(h) BSEM images corresponding to the SEM images in parts (a)-(d), respectively. The undoped ZnO NRs are grown under the standard condition. 


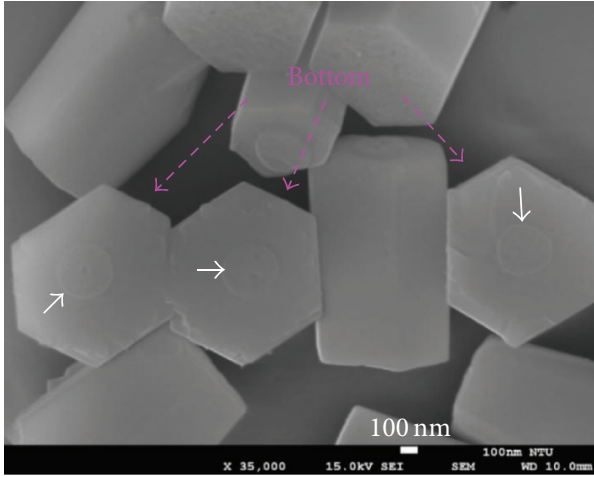

(a)

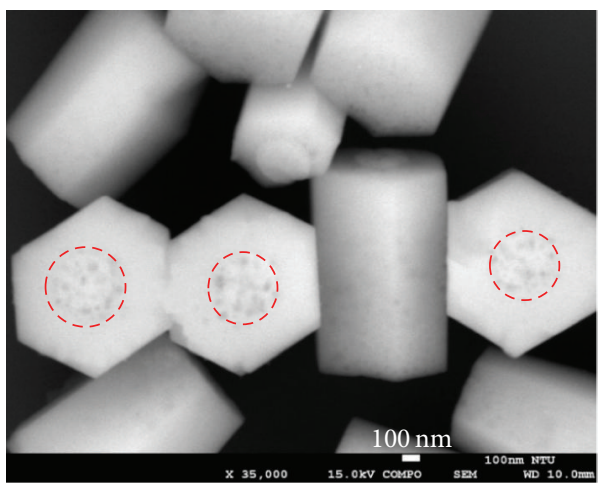

(c)

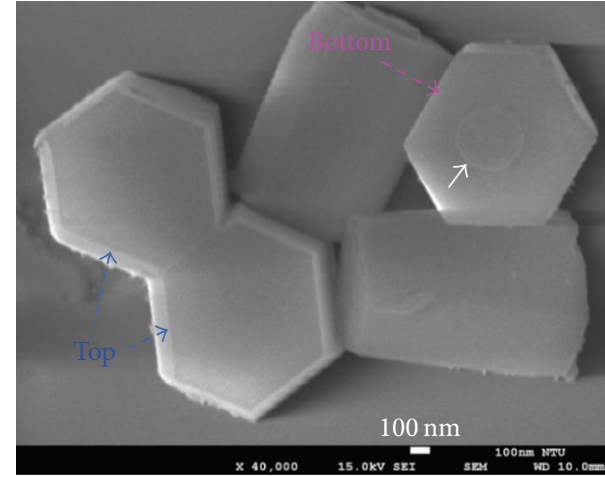

(b)

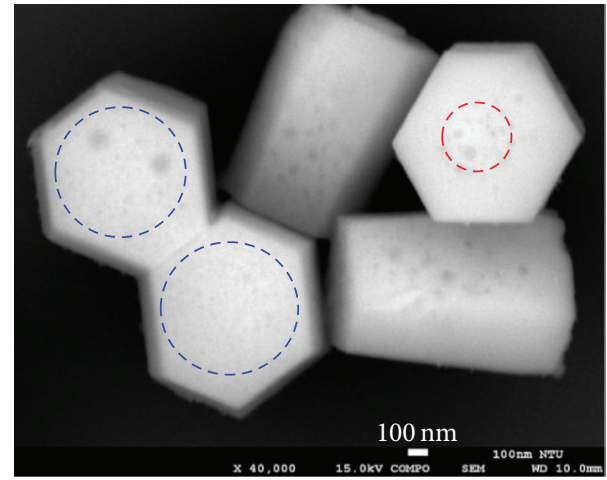

(d)

Figure 7: (a) and (b) SEM images of a few fallen ZnO NRs showing either their bottom or top faces after the three-stage annealing process (the same condition as the sample in Figure 6(d)). (c) and (d) The corresponding BSEM images of parts (a) and (b), respectively.

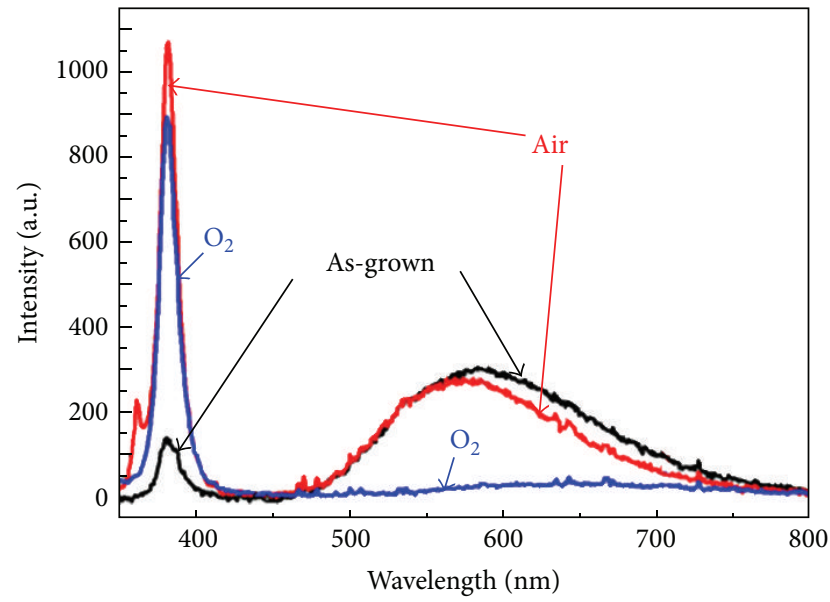

FIGURE 8: PL spectra of undoped $\mathrm{ZnO} \mathrm{NR}$ array samples under the as-grown condition and the thermal annealing conditions of different ambient gases (air and oxygen). The NR array samples are grown under the standard condition. The thermal annealing conditions include $300^{\circ} \mathrm{C}$ in temperature and $60 \mathrm{~min}$ in duration.

with ambient oxygen, respectively. One can see that thermal annealing can improve the optical quality of a $\mathrm{ZnO} \mathrm{NR}$ array sample, particularly when oxygen is used as the ambient gas. Therefore, oxygen was used as the ambient gas in the annealing processes leading to the results in Figures 3-7.

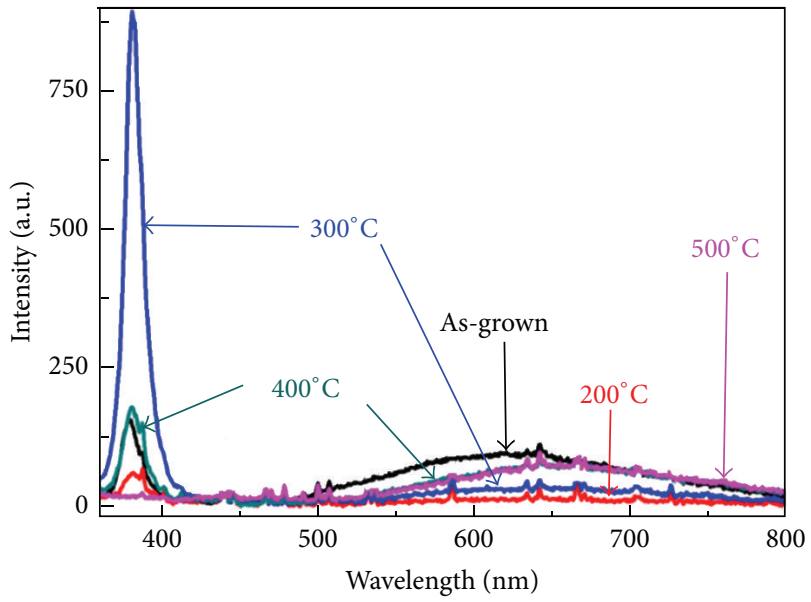

FIgURE 9: PL spectra of Ga-doped $\mathrm{ZnO} \mathrm{NR}$ array samples with different thermal annealing temperatures. The Ga-doped ZnO NRs are grown under the standard condition. The annealing process is undertaken with ambient oxygen for $60 \mathrm{~min}$.

Figure 9 shows the PL spectra of Ga-doped ZnO NR array samples at different thermal annealing temperatures. The result of the as-grown sample is also shown here for comparison. The Ga-doped $\mathrm{ZnO}$ NRs are grown under the standard condition. The annealing process is undertaken with ambient oxygen for $60 \mathrm{~min}$. Here, one can see that the defect emission level decreases first and then increases as the 


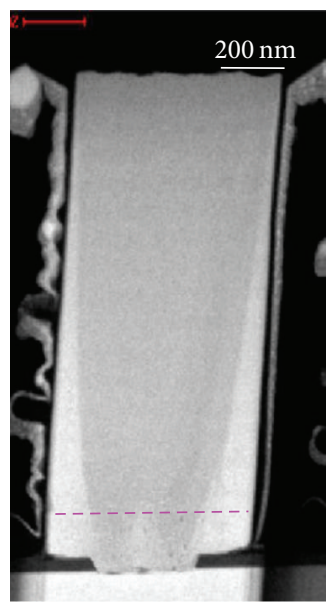

(a)

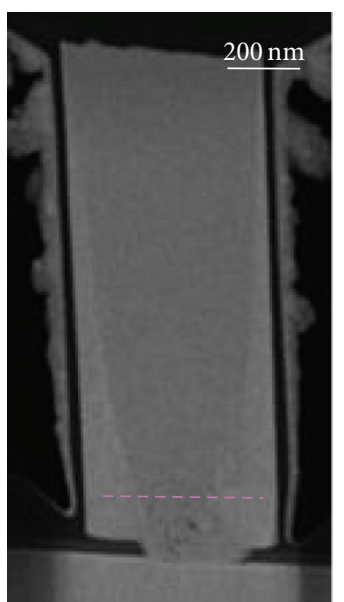

(b)

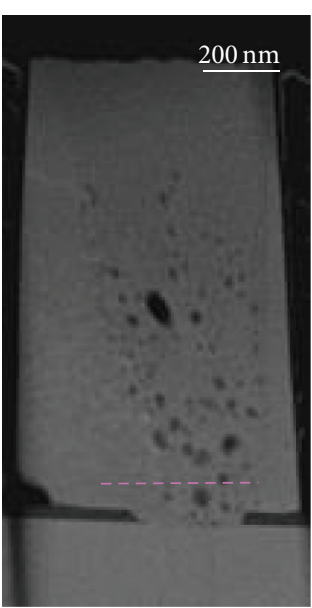

(c)

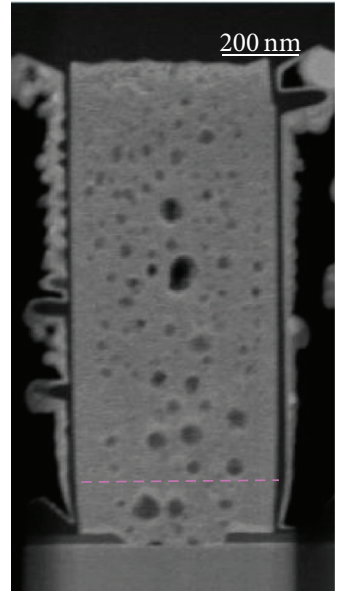

(d)

FIGURE 10: (a) HAADF image of an as-grown Ga-doped NR sample. (b)-(d) HAADF images of the Ga-doped ZnO NR samples after they are thermally annealed at 200,300 , and $400^{\circ} \mathrm{C}$, respectively. The Ga-doped ZnO NRs are grown under the standard condition. The annealing process is undertaken with ambient oxygen for $60 \mathrm{~min}$. In each of those images, a horizontal dashed line is drawn, along which EDX analysis is made.

TABLE 1: Ratio of integrated PL intensity of the ZnO band-edge emission over that of the defect emission with different Ga doping concentrations at different thermal annealing temperatures.

\begin{tabular}{lccccc}
\hline $\begin{array}{l}\text { Doping concentration } \\
\text { (M) }\end{array}$ & As-grown & $200^{\circ} \mathrm{C}$ & $300^{\circ} \mathrm{C}$ & $400^{\circ} \mathrm{C}$ & $500^{\circ} \mathrm{C}$ \\
\hline 0.002 & 0.24 & 0.43 & 1.69 & 0.18 & 0.08 \\
0.003 & 0.17 & 0.53 & 2.11 & 0.28 & 0.09 \\
0.004 & 0.15 & 0.55 & 0.84 & 0.22 & 0.01 \\
\hline
\end{tabular}

annealing temperature increases from 200 to $500^{\circ} \mathrm{C}$. At 400 and $500^{\circ} \mathrm{C}$ for thermal annealing, the spectral peak of defect emission red shifts. The ratio of integrated intensity between the band-edge and defect emissions is the largest when the annealing temperature is $300^{\circ} \mathrm{C}$. Table 1 shows the integrated PL intensity ratios of various samples with different Gadoping concentrations when they are annealed at different temperatures. The annealing is undertaken with ambient oxygen for $60 \mathrm{~min}$. Here, one can see that at the annealing temperature of $300^{\circ} \mathrm{C}$, we can always obtain the highest integrated intensity ratio under each doping condition. The ratio is the highest when the doping concentration is $0.003 \mathrm{M}$. Therefore, $0.003 \mathrm{M}$ in gallium nitrate hydrate concentration and $300^{\circ} \mathrm{C}$ in annealing temperature represent the optimum conditions for forming Ga-doped $\mathrm{ZnO} \mathrm{NR}$ arrays based on the hydrothermal method as far as optical property is concerned.

\section{Discussions}

Figures 10(b)-10(d) show the HAADF images of Ga-doped $\mathrm{ZnO} \mathrm{NR}$ array samples when they are thermally annealed at 200,300 , and $400^{\circ} \mathrm{C}$, respectively. For comparison, the HAADF image of the as-grown sample is also shown in Figure 10(a). The doped $\mathrm{ZnO}$ NRs are grown under the standard condition. The annealing process is undertaken with ambient oxygen for $60 \mathrm{~min}$. In each part of Figure 10, one can see the darker and brighter regions of vertical and lateral growths, respectively, indicating that the vertical growth region is oxygen richer, when compared with the lateral growth region, because the signal intensity in a HAADF image is proportional to average atomic number. The contrast between the vertical and lateral growth regions diminishes as the annealing temperature becomes higher. In each of those images, a horizontal dashed line is drawn, along which EDX analysis is made. The atomic \% levels of $\mathrm{O}, \mathrm{Zn}$, and $\mathrm{Ga}$ along the dashed lines in Figures 10(a)-10(d) are shown in Figures 11(a)-11(d), respectively. It is noted that in each case, the dashed line passes the boundaries between the vertical and lateral growth regions. In each part of Figure 11, data points $1,2,7$, and $8(3-6)$ are located in the lateral (vertical) growth region. As shown in Figure 11(a), the oxygen atomic composition \% is higher than that of zinc in both regions of vertical and lateral growths. The difference between the oxygen and zinc contents in the vertical growth region is significantly larger than that in the lateral growth region, indicating that the crystal in the lateral growth region is closer to the stoichiometric condition. The oxygen-richer condition in the vertical growth region is the major cause for easier formation of void. The gallium atomic \% is low and quite uniform over the two growth regions. When the sample is thermally annealed, the difference between the oxygen and zinc contents becomes smaller in either the vertical or lateral growth region. The difference level decreases with increasing annealing temperature. At $400^{\circ} \mathrm{C}$ in annealing temperature, both atomic \% levels of oxygen and zinc become close to $50 \%$. The difference between the vertical and lateral growth regions diminishes due to desorption of excess oxygen atoms during the process of thermal annealing.

As shown in Figure 9, the defect emission level decreases at the thermal annealing temperatures of 200 and $300^{\circ} \mathrm{C}$ 


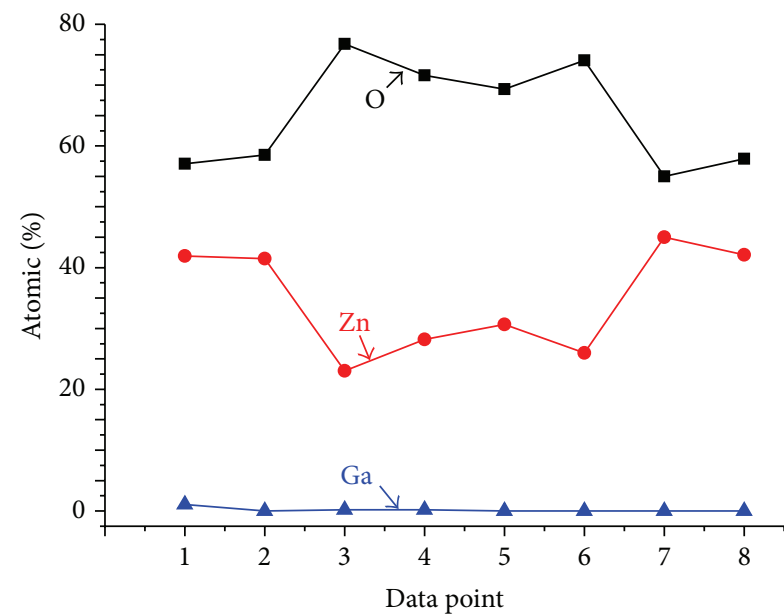

(a)

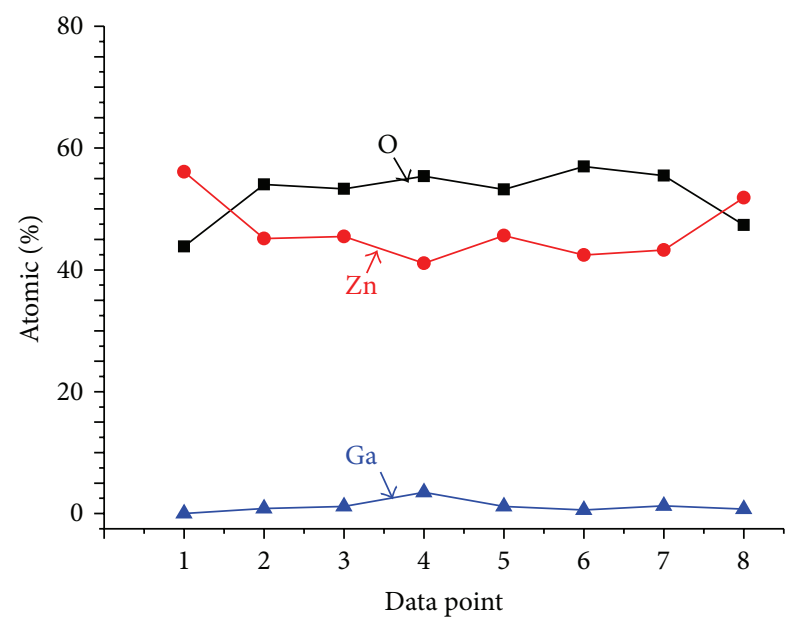

(c)

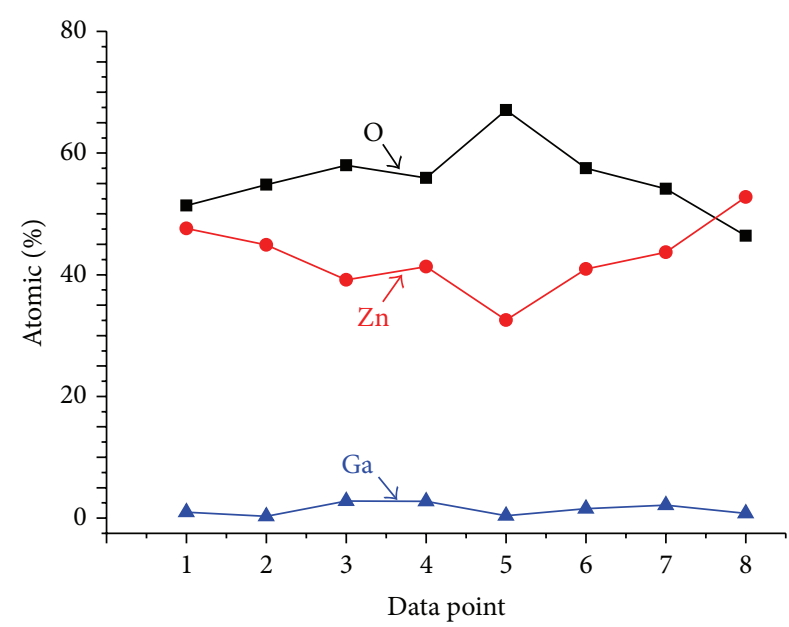

(b)

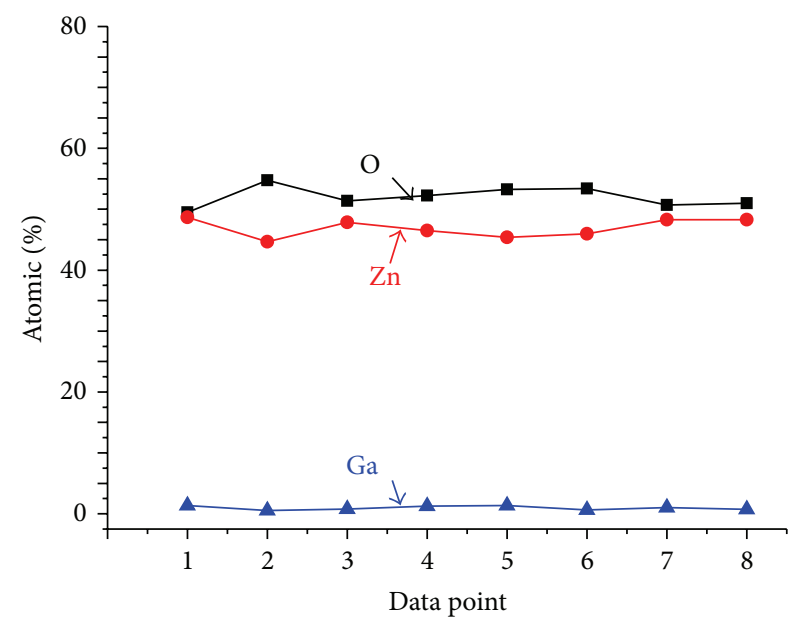

(d)

Figure 11: (a)-(d) Atomic \% levels of O, Zn, and Ga along the dashed lines in Figures 10(a)-10(d), respectively. In each part, data points 1, 2, 7 , and 8 (3-6) are located in the lateral (vertical) growth region.

and then increases as the annealing temperature is raised to 400 and $500^{\circ} \mathrm{C}$. It is noted that the emission spectral peak is red shifted from $\sim 620$ to $\sim 660 \mathrm{~nm}$ when the annealing temperature is increased from 200 to $500^{\circ} \mathrm{C}$. The defect emission band can be split into two components, including one centered at $\sim 590 \mathrm{~nm}$ (yellow emission) and the other centered at $\sim 690 \mathrm{~nm}$ (red emission). The red emission in a $\mathrm{ZnO}$ sample grown with the hydrothermal method has been attributed to oxygen interstitials $[17,20]$. The yellow emission was partly attributed to oxygen interstitials [21]. It was also ascribed to the presence of hydroxyl groups in the sample, which are commonly observed in a sample with a solution growth method [22]. The hydroxyl groups are involved in the crystallization of $\mathrm{ZnO} \mathrm{NRs}$ by substituting oxygen anions at their positions [17]. During the annealing process, the hydroxyl groups gain the energy required to escape from their crystal lattice sites. The desorption rate reaches the peak level at $150^{\circ} \mathrm{C}$ in annealing temperature [22]. Hence, the reduction of hydroxyl groups in $\mathrm{ZnO}$ lattice may be responsible for the decrease of the yellow emission level in the PL spectrum. With ambient oxygen during thermal annealing, ambient oxygen can be absorbed by the NRs while oxygen interstitials can evade from NRs at the same time. When the annealing temperature is lower than $400^{\circ} \mathrm{C}$, the process of oxygen desorption may dominate such that the red emission caused by excess oxygen becomes weaker. As the annealing temperature becomes higher, the process of oxygen absorption dominates such that the red emission level becomes higher. On the other hand, during thermal annealing at a high temperature, no supply of hydroxyl groups can lead to the increase of yellow emission. It is noted that the aforementioned increase of oxygen interstitials under the conditions of 400 and $500^{\circ} \mathrm{C}$ in annealing temperature can occur only in a thin subsurface layer on a $\mathrm{ZnO} \mathrm{NR}$, particularly near the bottom of an NR where the supply of ambient oxygen is smaller. In this situation, the increase of oxygen interstitials near the NR top can be monitored to show the increase of red emission (and effectively the red shift of the overall defect emission spectrum) with the PL measurement under the conditions of shallow penetration $(\sim 100 \mathrm{~nm}$ in 
depth from the NR surface) and shadowed illumination of UV excitation laser. However, in the EDX measurement with the results shown in Figure 11, the locations for acquiring the data are close to the NR bottom (see the dashed lines in Figure 10) where the increase of oxygen interstitials is insignificant such that the stoichiometric condition can be almost reached, as shown in Figure 11(d).

The formation of voids can be attributed to the desorption of hydroxyl groups during the annealing process [17]. In the $\mathrm{ZnO}$ crystal with hydroxyl groups, to maintain local electrical neutrality, cation vacancies must exist to neutralize the additional positive charges of hydrogen ions in the hydroxyl groups. During thermal annealing, the hydroxyl groups leave the sample in the form of water vapor and generate anion vacancies at their originally resting sites. The cation vacancies react with the anion vacancies to form vacancy pairs. The gathering of vacancy pairs forms the cores of the voids. With the thermal energy, a few small voids can merge into a larger one at a higher annealing temperature.

The speed of vertical growth is much higher than that of lateral growth in forming a $\mathrm{ZnO} \mathrm{NR}$. The higher growth speed in the vertical direction leads to poorer crystal quality with abundant defects [19]. As shown in Figures 3 and 4, void formation can be observed in the vertical growth region at lower thermal annealing temperatures, implying that the density of hydroxyl groups is higher in the vertical growth region, when compared with the lateral growth region. One of the reasons for vertical growth being more defective is the polarity along the $\mathrm{c}$-axis owing to the hexagonal wurtzite structure of $\mathrm{ZnO}$ [23]. The top polar plane is more attractive to hydroxyl groups when compared with the nonpolar plane on the sidewall of a $\mathrm{ZnO}$ NR. The nonuniform void distribution along the c-axis in an NR under the thermal annealing conditions at 300 and $400^{\circ} \mathrm{C}$ in temperature (see Figures 3 and 4) can be attributed to the temperature gradient (decreasing temperature from the bottom to the top of an $\mathrm{NR}$ ) in thermally annealing the NR sample. Although the desorption rate of hydroxyl groups decreases with increasing annealing temperature beyond $150^{\circ} \mathrm{C}$ [24], only when the annealing temperature is high enough for the void cores to grow into small voids and for the small voids to merge into large voids such that they can be observed with TEM. In Figures $3(\mathrm{c}), 3(\mathrm{~d})$, and $4(\mathrm{c})$, the void cores or small voids near the NR tops are too small to be observed.

\section{Conclusions}

In summary, we have investigated the void structures and related optical properties after thermal annealing with ambient oxygen in regularly patterned $\mathrm{ZnO} \mathrm{NR}$ arrays grown with the hydrothermal method. In increasing the annealing temperature, based on the TEM and BSEM observations, void distribution started from the bottom and extended to the top of an NR in the vertical growth region. When the annealing temperature became higher than $400^{\circ} \mathrm{C}$, void distribution spread into the lateral growth region. PL measurement showed that the $\mathrm{ZnO}$ band-edge emission, in contrast to defect emission in the yellow-red range, was the strongest under the $n-\mathrm{ZnO}$ NR process conditions of $0.08 \mathrm{M}$ in growth solution concentration, $0.003 \mathrm{M}$ in Ga-doping concentration, $80^{\circ} \mathrm{C}$ in growth temperature, $180 \mathrm{~min}$ in growth duration, and $300^{\circ} \mathrm{C}$ in thermal annealing temperature with ambient oxygen for $60 \mathrm{~min}$. EDX data indicated that the concentration of hydroxyl groups, which took the positions of anions in $\mathrm{ZnO}$, in the vertical growth region was significantly higher than that in the lateral growth region of an NR. During thermal annealing, hydroxyl groups were desorbed from the NR leaving anion vacancies for reacting with cation vacancies to form void cores. The thermal annealing process provided energy for merging small voids into large ones.

\section{Conflict of Interests}

The authors declare that there is no conflict of interests regarding the publication of this paper.

\section{Acknowledgment}

This research was supported by National Science Council, Taiwan, The Republic of China, under the Grants of NSC 1012120-M-002-013, NSC 101-2622-E-002-002-CC2, NSC 992221-E-002-123-MY3, and NSC 101-2221-E-002-153, by the Excellent Research Projects of National Taiwan University (101R890952 and 101R890951) and by US Air Force Scientific Research Office under the Ccontract of AOARD-12-4068.

\section{References}

[1] W. I. Park and G.-C. Yi, "Electroluminescence in n-ZnO Nanorod Arrays Vertically Grown on p-GaN," Advanced Materials, vol. 16, no. 1, pp. 87-90, 2004.

[2] M. Law, L. E. Greene, J. C. Johnson, R. Saykally, and P. Yang, "Nanowire dye-sensitized solar cells," Nature Materials, vol. 4, no. 6, pp. 455-459, 2005.

[3] Y. Qin, X. Wang, and Z. L. Wang, "Microfibre-nanowire hybrid structure for energy scavenging," Nature, vol. 451, no. 7180, pp. 809-813, 2008.

[4] M. H. Huang, S. Mao, H. Feick et al., "Room-temperature ultraviolet nanowire nanolasers," Science, vol. 292, no. 5523, pp. 18971899, 2001.

[5] Y.-J. Lee, D. S. Ruby, D. W. Peters, B. B. McKenzie, and J. W. $\mathrm{P}$. Hsu, "ZnO nanostructures as efficient antireflection layers in solar cells," Nano Letters, vol. 8, no. 5, pp. 1501-1505, 2008.

[6] S.-W. Lee, M.-C. Jeong, J.-M. Myoung, G.-S. Chae, and I.-J. Chung, "Magnetic alignment of $\mathrm{ZnO}$ nanowires for optoelectronic device applications," Applied Physics Letters, vol. 90, no. 13, Article ID 133115, 2007.

[7] Y. J. Hong, H. S. Jung, J. Yoo et al., "Shape-controlled nanoarchitectures using nanowalls," Advanced Materials, vol. 21, no. 2, pp. 222-226, 2009.

[8] L. E. Jensen, M. T. Björk, S. Jeppesen, A. I. Persson, B. J. Ohlsson, and L. Samuelson, "Role of surface diffusion in chemical beam epitaxy of InAs nanowires," Nano Letters, vol. 4, no. 10, pp. 19611964, 2004.

[9] C.-H. Lee, J. Yoo, Y. J. Hong et al., " $\mathrm{GaN} / \mathrm{In}_{1-x} \mathrm{Ga}_{x} \mathrm{~N} / \mathrm{GaN} / \mathrm{ZnO}$ nanoarchitecture light emitting diode microarrays," Applied Physics Letters, vol. 94, no. 21, Article ID 213101, 2009. 
[10] W. I. Park, G.-C. Yi, J.-W. Kim, and S.-M. Park, "Schottky nanocontacts on ZnO nanorod arrays," Applied Physics Letters, vol. 82, no. 24, pp. 4358-4360, 2003.

[11] A. K. Sharma, J. Narayan, J. F. Muth et al., "Optical and structural properties of epitaxial $\mathrm{Mg}_{x} \mathrm{Zn}_{1-x} \mathrm{O}$ alloys," Applied Physics Letters, vol. 75, no. 21, pp. 3327-3329, 1999.

[12] T. Minemoto, T. Negami, S. Nishiwaki, H. Takakura, and Y. Hamakawa, "Preparation of $\mathrm{Zn}_{1-x} \mathrm{Mg}_{x} \mathrm{O}$ films by radio frequency magnetron sputtering," Thin Solid Films, vol. 372, no. 1, pp. 173-176, 2000.

[13] M.-H. Jung and H. Lee, "Open selective patterning of zno nanorods on silicon substrates using nanoimprint lithography," Nanoscale Research Letters, vol. 6, article 159, 2011.

[14] Y. Wei, W. Wu, R. Guo, D. Yuan, S. Das, and Z. L. Wang, "Waferscale high-throughput ordered growth of vertically aligned ZnO nanowire arrays," Nano Letters, vol. 10, no. 9, pp. 34143419, 2010.

[15] S. Xu, Y. Wei, M. Kirkham et al., "Patterned growth of vertically aligned $\mathrm{ZnO}$ nanowire arrays on inorganic substrates at low temperature without catalyst," Journal of the American Chemical Society, vol. 130, no. 45, pp. 14958-14959, 2008.

[16] J. J. Dong, X. W. Zhang, Z. G. Yin et al., "Controllable growth of highly ordered $\mathrm{ZnO}$ nanorod arrays via inverted self-assembled monolayer template," ACS Applied Materials and Interfaces, vol. 3, no. 11, pp. 4388-4395, 2011.

[17] J. J. Richardson, G. K. L. Goh, H. Q. Le, L.-L. Liew, F. F. Lange, and S. P. Denbaars, "Thermally induced pore formation in epitaxial $\mathrm{ZnO}$ films grown from low temperature aqueous solution," Crystal Growth and Design, vol. 11, no. 8, pp. 3558-3563, 2011.

[18] S. M. Jeon, M. S. Kim, M. Y. Cho et al., "Fabrication of porous $\mathrm{ZnO}$ nanorods with nano-sized pores and their properties," Journal of the Korean Physical Society, vol. 57, no. 6, pp. 14771481, 2010.

[19] J. M. Stiegler, R. Tena-Zaera, O. Idigoras, A. Chuvilin, and R. Hillenbrand, "Correlative infrared-electron nanoscopy reveals the local structure-conductivity relationship in zinc oxide nanowires," Nature Communications, vol. 3, article 1131, 2012.

[20] J.-W. Cai, J.-P. Xu, X.-S. Zhang et al., "Defect-related visible luminescence of $\mathrm{ZnO}$ nanorods annealed in oxygen ambient," Optoelectronics Letters, vol. 8, no. 1, pp. 4-8, 2012.

[21] A. B. Djurišić, Y. H. Leung, K. H. Tam et al., "Green, yellow, and orange defect emission from $\mathrm{ZnO}$ nanostructures: influence of excitation wavelength," Applied Physics Letters, vol. 88, no. 10, Article ID 103107, 2006.

[22] K. H. Tam, C. K. Cheung, Y. H. Leung et al., "Defects in $\mathrm{ZnO}$ nanorods prepared by a hydrothermal method," Journal of Physical Chemistry B, vol. 110, no. 42, pp. 20865-20871, 2006.

[23] K. S. Kim, H. Jeong, M. S. Jeong, and G. Y. Jung, "Polymer-templated hydrothermal growth of vertically aligned single-crystal $\mathrm{ZnO}$ nanorods and morphological transformations using structural polarity," Advanced Functional Materials, vol. 20, no. 18, pp. 3055-3063, 2010.

[24] R. Xie, T. Sekiguchi, T. Ishigaki et al., "Enhancement and patterning of ultraviolet emission in $\mathrm{ZnO}$ with an electron beam," Applied Physics Letters, vol. 88, no. 13, Article ID 134103, 2006. 

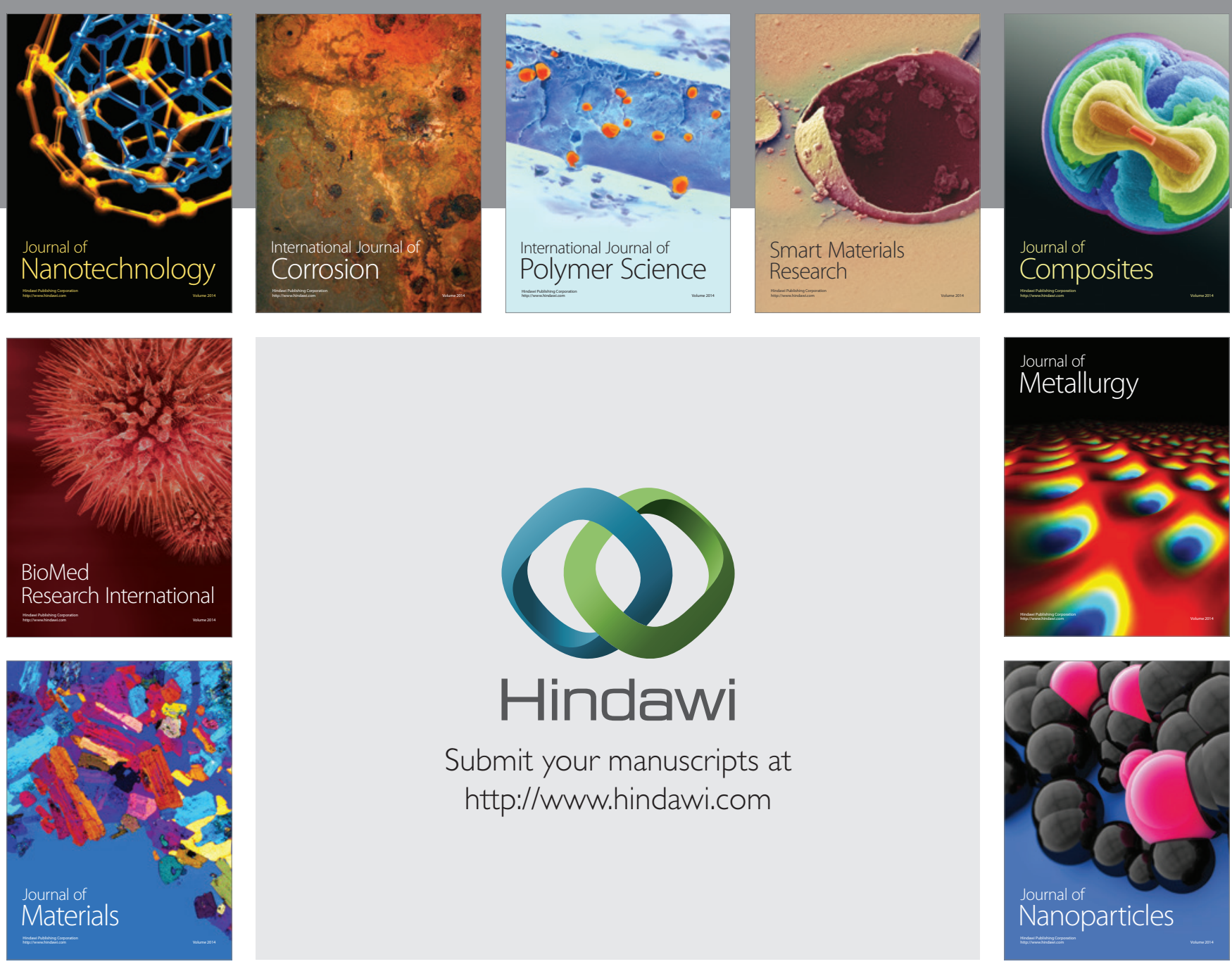

Submit your manuscripts at http://www.hindawi.com
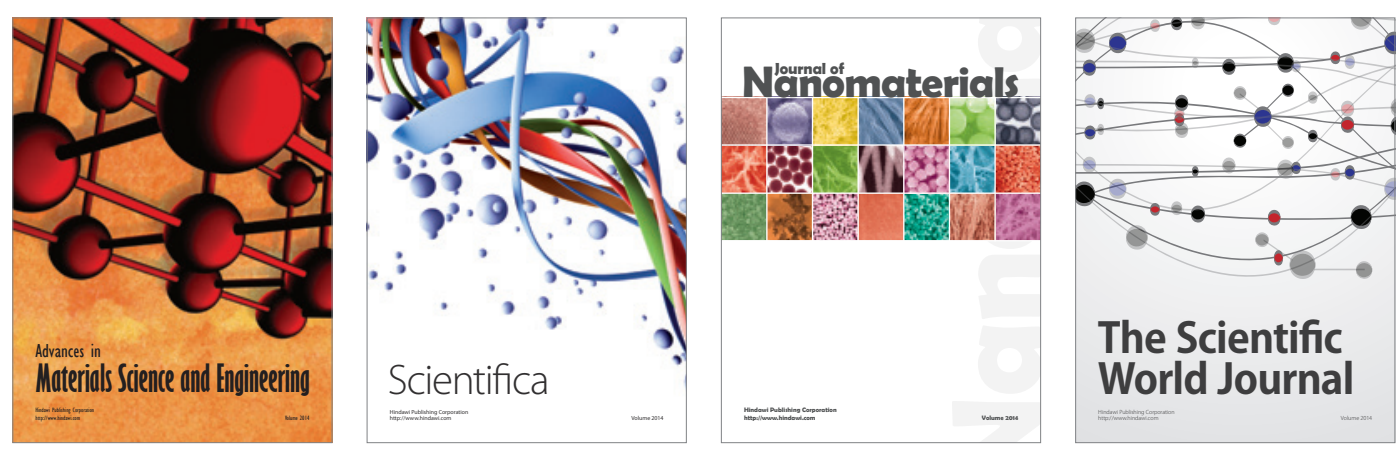

\section{The Scientific World Journal}
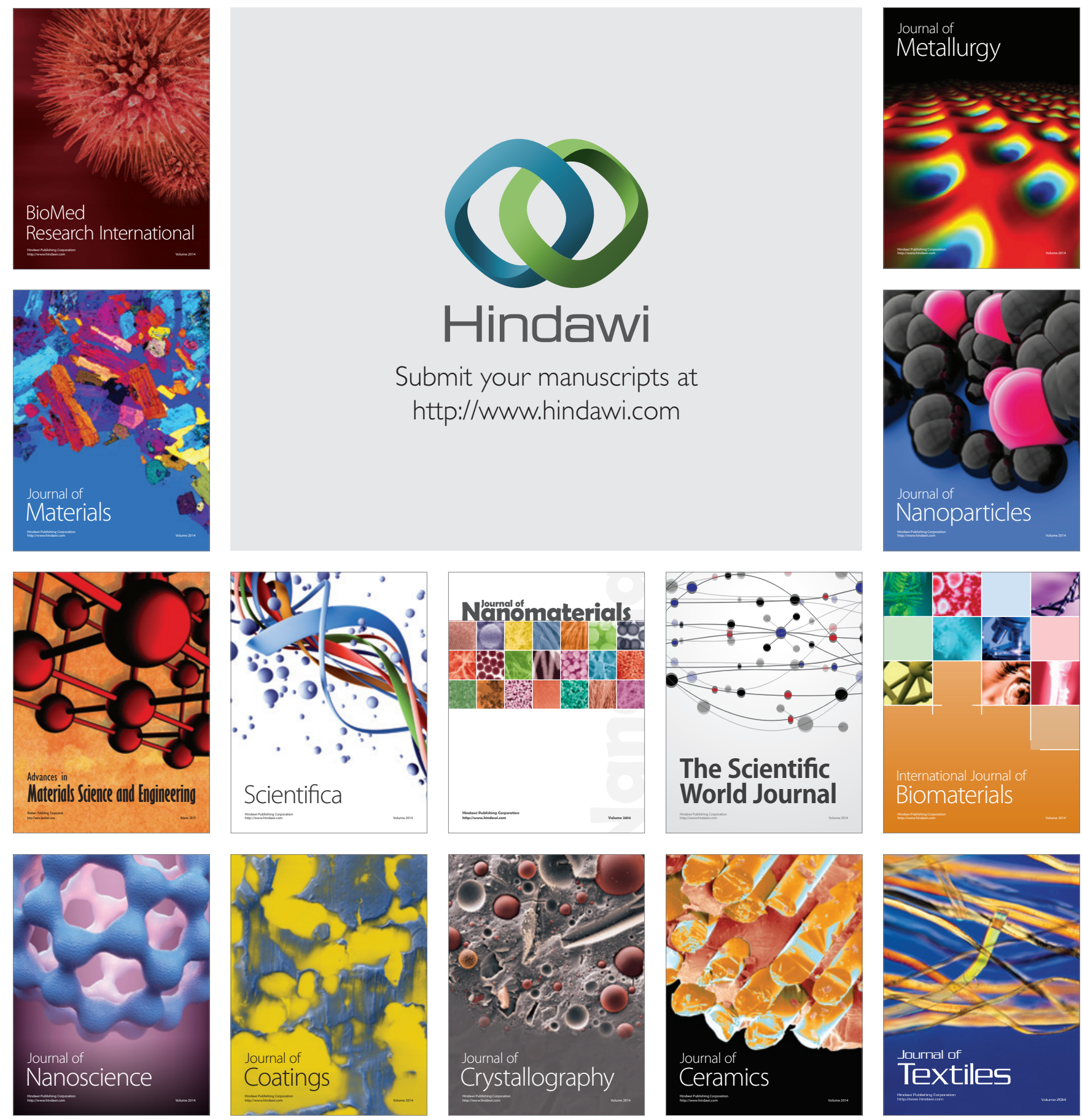